\title{
Benefits of photograph transmission for trauma management in isolated areas: cases from the French tele-medical assistance service
}

\author{
Emilie Dehours, Marie-Laure Tourneret, Patrick Roux, Julien Tabarly
}

Centre de Consultations Médicales Maritimes, SAMU 31, CHU Toulouse, France

\begin{abstract}
French maritime tele-medical assistance is currently performed by a telephone consultation associated with complementary transmission of data (photographs, electrocardiograms, etc.) over the internet. Five case reports are presented to illustrate how photo transmission is useful to managing initial care and monitoring isolated patients. Case reports included: Case 1: management of a hand burn; Case 2: management of a finger wound; Case 3: management of an ocular foreign body; Case 4: management of a subungual haematoma; Case 5: management of phlegmon. In conclusions, photo transmission improves our practice of maritime tele-medical medicine. New high-definition technologies will help in the development of videoconferences on ships.
\end{abstract}

(Int Marit Health 2016; 67, 2: 83-87)

\section{Key words: French Tele-Medical Assistance Service, tele-consultation, maritime, photographs}

\section{INTRODUCTION}

Caring for patients on ships has always been the captain's responsibility. Facing medical issues alone, for the last 30 years he has initially been able to undertake medical tele-consultations with a physician at the French Tele-Medical Assistance Service (TMAS) in Toulouse. The role of the TMAS physician is to provide a permanent tele-medical consultation and assistance service free of charge for everyone on board French or foreign ships. Medical tele-consultation is currently based on telephone consultations and the additional transmission of data (photographs, electrocardiograms) over the internet. The generalised use of photo transmission over the last 10 years has given rise to a real evolution in our practices. Indeed, the clinical and therapeutic management of patients on ships has improved, as has the rate of rerouting and evacuation. We present several clinical cases to illustrate the benefits of transmitting photographs as a real tele-medicine tool for medical tele-consultation in an isolated environment: the maritime environment.

\section{CASE NO. 1}

A call from the captain of an oil tanker in the China Seas. The 55-year-old Bulgarian mechanic had burned his hand with boiling water. The clinical examination carried out by the on-board care manager revealed blisters on his fingers and the back of his hand. The photographs sent showed two large blisters on the back of his hand and on the back of the third finger on his left hand without circular affliction - second degree burns (Fig. 1A). After receiving an opinion from the TMAS physician, the captain popped the blisters. He instituted an oral analgesic treatment and a local treatment (disinfection with chlorhexidine and application of silver sulfadiazine twice a day). The patient was treated completely on board until complete healing. Photograph transmission for 11 days enabled the TMAS physician to monitor healing (Fig. 1B, C, D).

\section{CASE NO. 2}

On board an oil tanker off Singapore, a 52-year-old Belgian mechanic presented an injury on the back of 


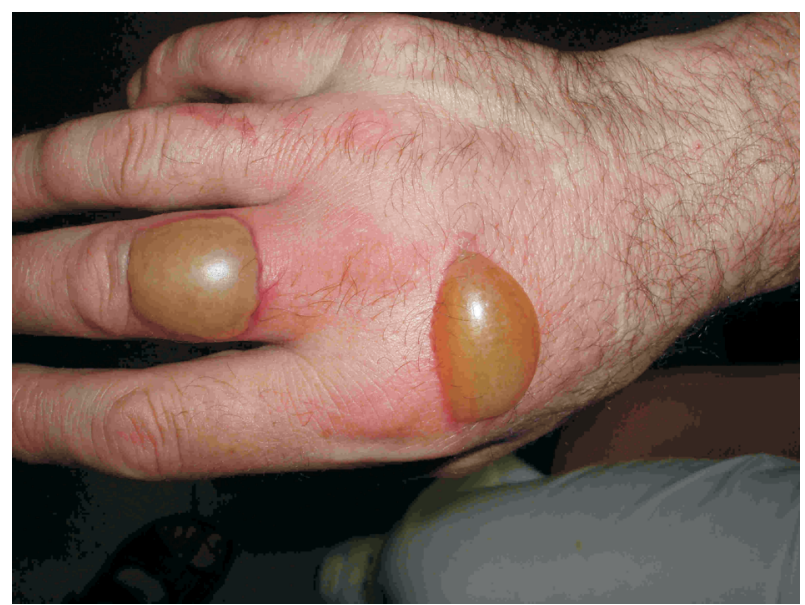

Figure 1A. Burn at day 1

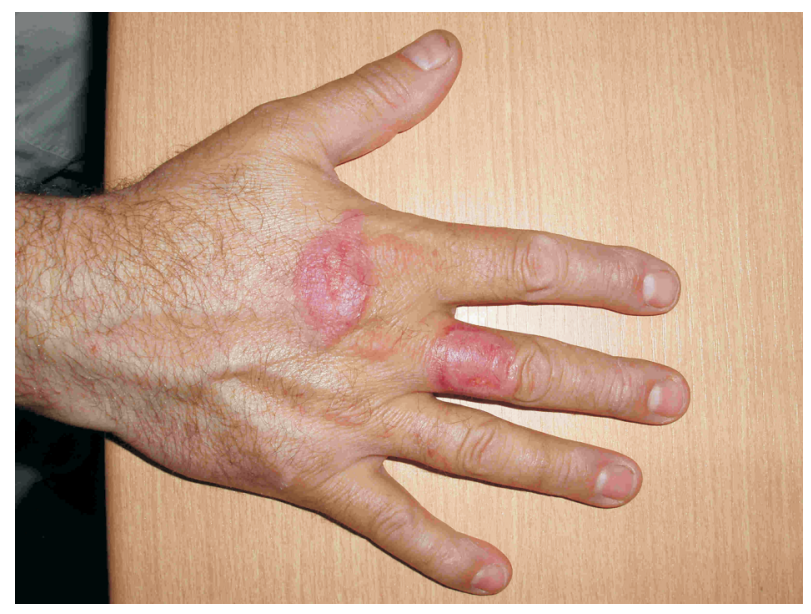

Figure 1C. Burn at day 7

a finger suffered with a dirty sharp object in the engine room. The clinical testing and exploration carried out by the onboard care manager when the call was made found a $2-\mathrm{cm}$ by $0.4 \mathrm{~cm}$ wound of little depth without neurovascular or tendon damage. The patient had no particular medical history or allergies, and his vaccinations were up to date. The TMAS physician asked for a photograph in order to determine whether stitches could be applied on board or if the patient needed to be evacuated (Fig. 2A). Upon receipt of the file, the injury was disinfected and an antibiotic treatment was instituted. Stitches were applied on board (Fig. 2B) by the captain, who had been trained for this, with a photograph transmitted at the end of the procedure (Fig. 2C). Monitoring and local care were done on board. At 20 days, the case was closed after complete removal of the stitches with healing and no sequelae.

\section{CASE NO. 3}

The captain of an oil tanker located in Indonesian waters called the TMAS for a 38-year-old sailor. He came to the ship's

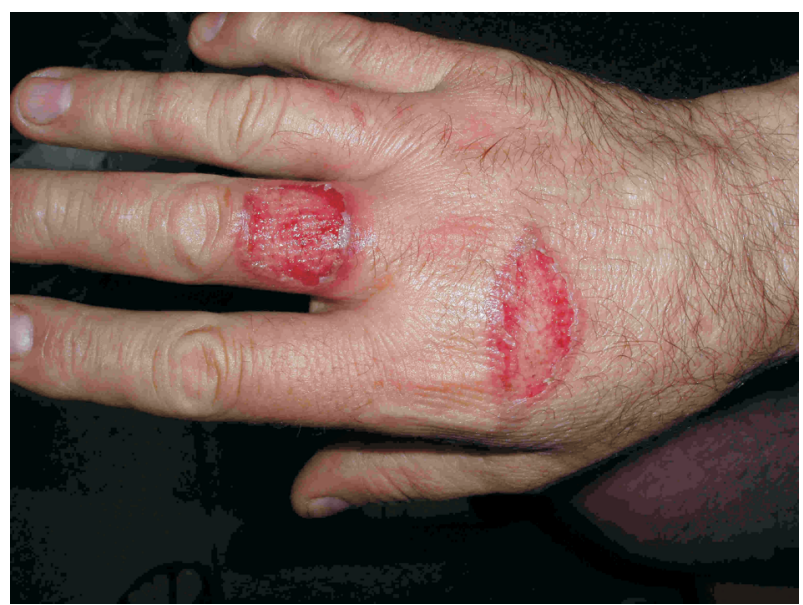

Figure 1B. Burn at day 2

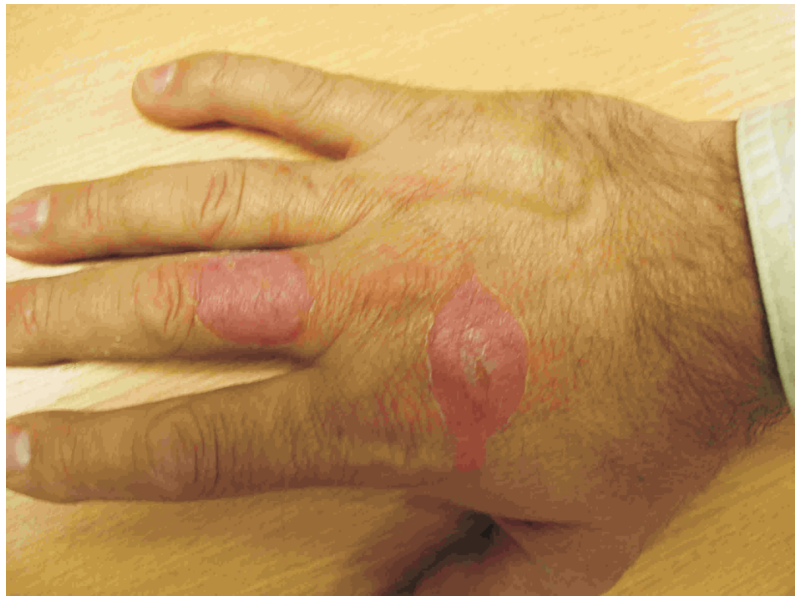

Figure 1D. Burn at day 12

infirmary with a painful red eye after the projection of iron filings. The clinical examination showed a black foreign body on the outside edge of the iris (Fig. 3A) and a fluorescein test was performed (Fig. 3B). After receiving the two photographs and calling the ship back, the TMAS physician recommended that the captain remove the foreign body with the special curette present on board. After several attempts, the foreign body was removed from the eye and a check with the fluorescein test found that the bottom of the injury was clear. The physician continued the tele-consultation by prescribing a treatment including ocular washings (boric acid, sodium borate), antibiotic eye drops (ciprofloxacin) and an ocular healing agent (vitamin A). The patient was sent for consultation with an ophthalmologist during a scheduled call at Singapore 4 days later for a specialised examination. Healing was achieved without sequelae.

\section{CASE NO. 4}

The captain of an oil tanker, two days out from the Strait of Gibraltar, placed a call for his 30-year-old, right-handed 


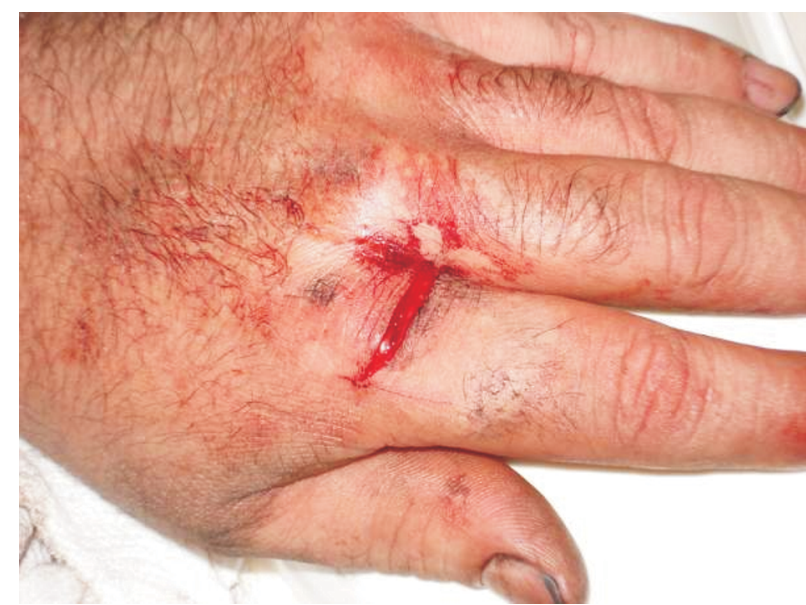

Figure 2A. Wound

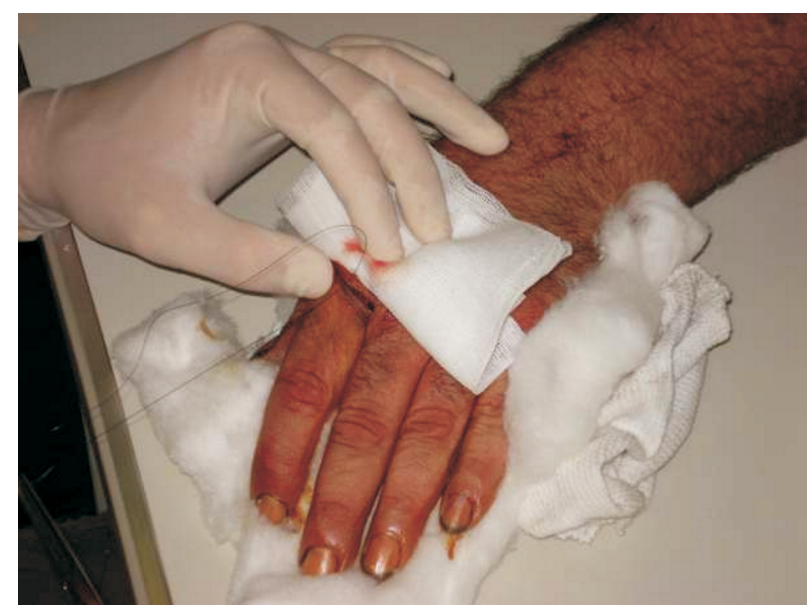

Figure 2B. Application of stitches

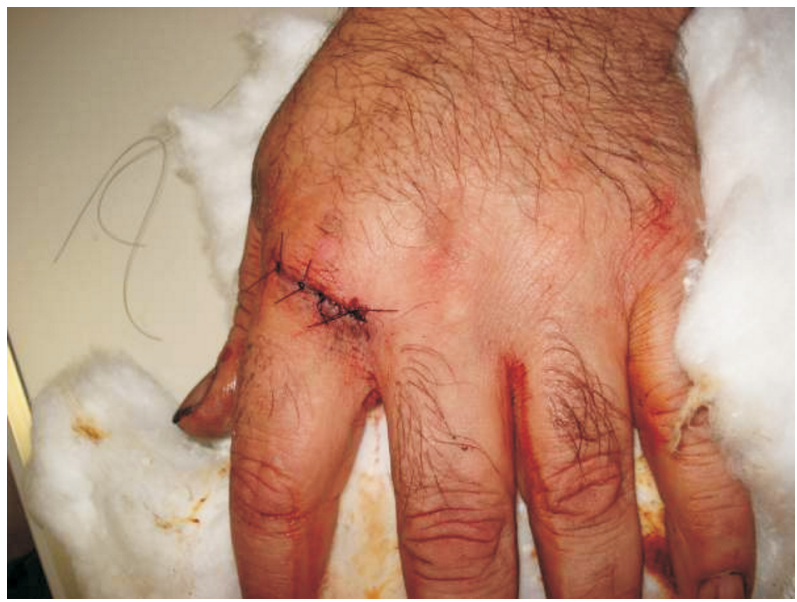

Figure 2C. Stitches applied by the captain

chief mate whose third finger on his right hand got caught in a metal door. The examination undertaken by the captain found a bruise on the third finger with no open wound, no

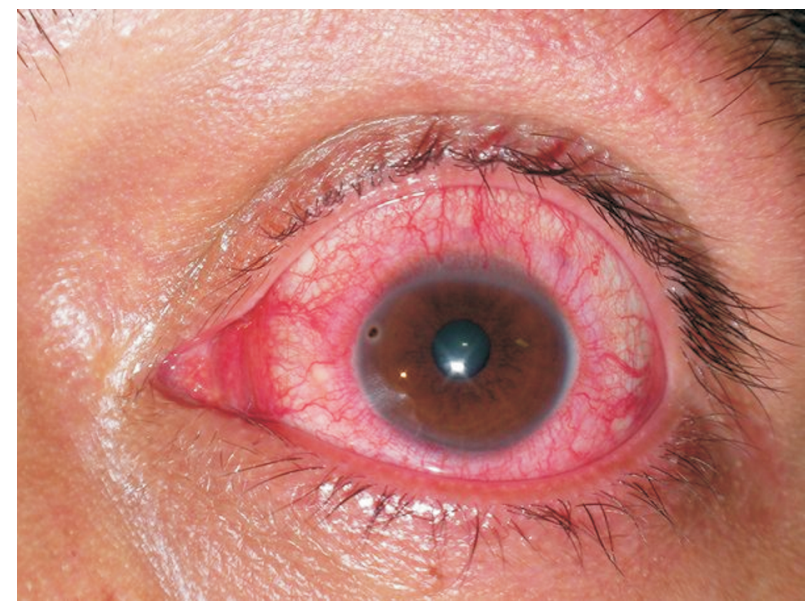

Figure 3A. Foreign body visible to the naked eye

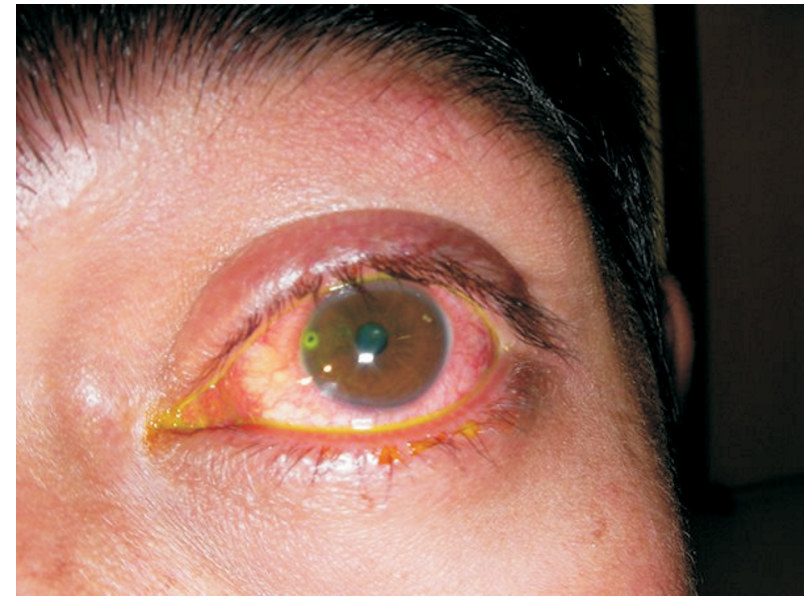

Figure 3B. Eye examination after a fluorescein test

deformation, no neurovascular impairment and a subungual haematoma. After sending a first photograph (Fig. 4A), the physician asked the captain to drain the subungual haematoma (Fig. 4B, C). The patient was given an analgesic (paracetamol) and placed under clinical surveillance as explained to the captain. The patient remained on board the ship and no sequelae were observed.

\section{CASE NO. 5}

The French captain of a fishing vessel, a Spanish netter, called for a 34-year-old Portuguese sailor. Four days earlier, the sailor had been stung by a hake on the middle finger of his left hand. The clinical examination performed by the captain when the call was made to the TMAS found a trace of the sting on the back of the middle finger of his left hand, with redness and an oedema covering the hand up to the wrist. He felt weak; no fever was observed, with limited movement in his fingers. The vessel was off the Irish coast, $15 \mathrm{~h}$ from the nearest port, and helicopter evacuation was 


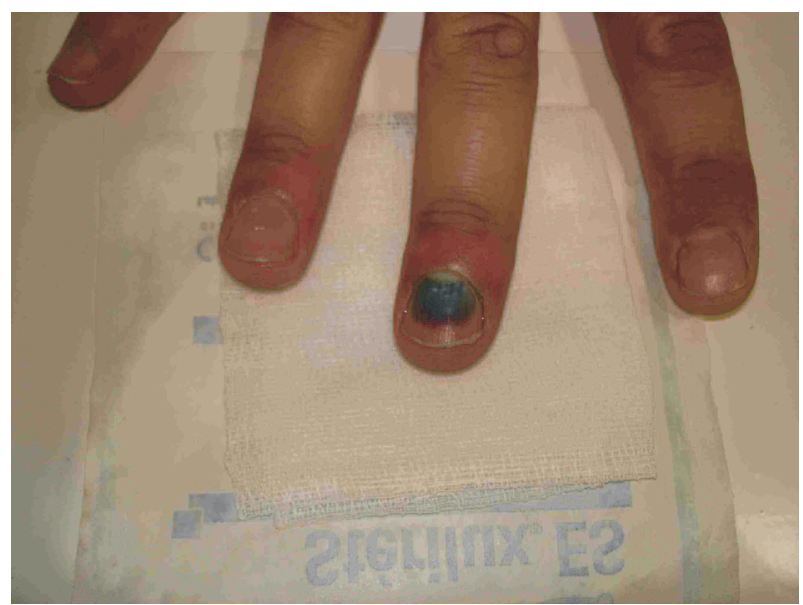

Figure 4A. Subungual haematoma

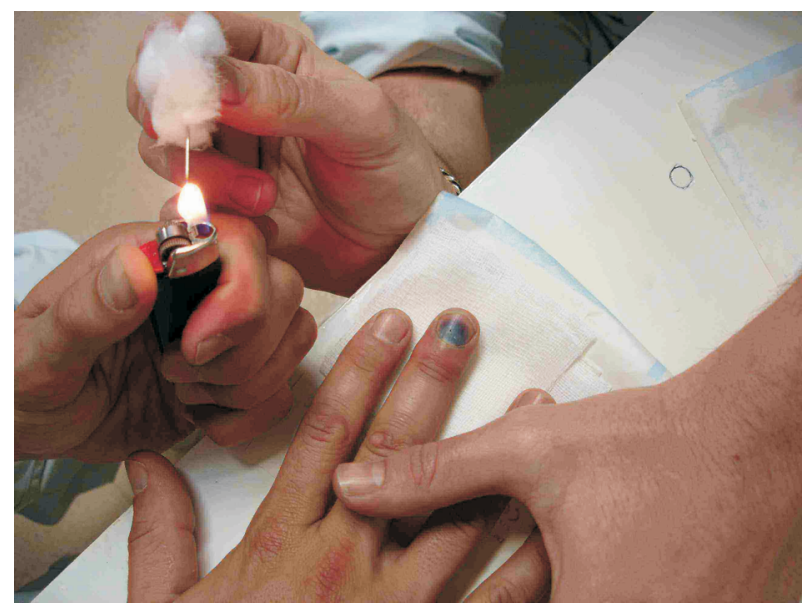

Figure 4B. Removal of the subungual haematoma

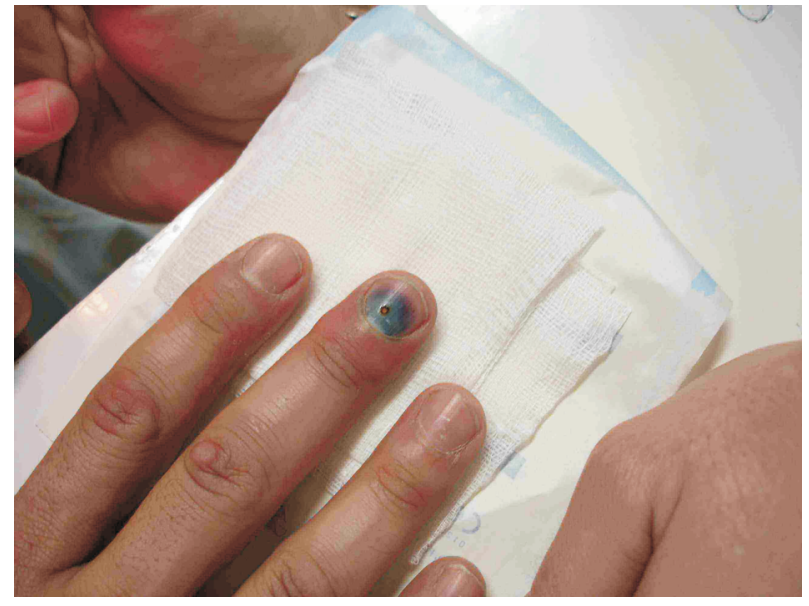

Figure 4C. Nail after removal of the haematoma

possible in cooperation with the Irish emergency services. Faced with this clinical presentation suggesting phlegmon of the hand, the TMAS physician asked for a photograph to be sent to him (Fig. 5A) to make a therapeutic and opera-

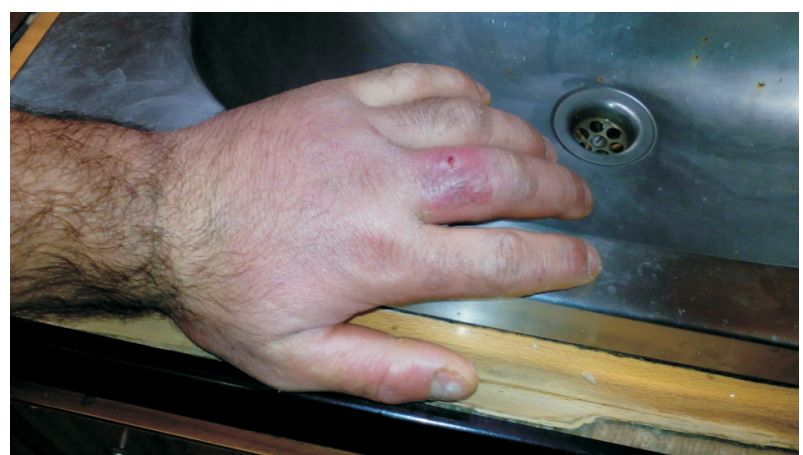

Figure 5A. Phlegmon on the back of the hand

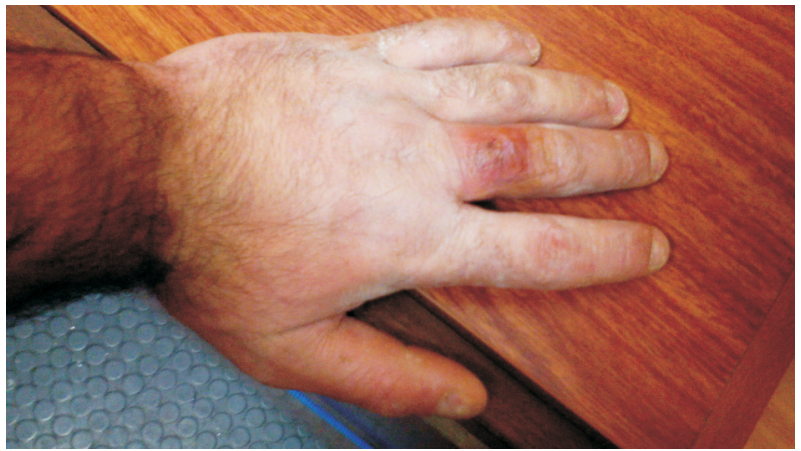

Figure 5B. Evolution of the infection at day 4

tional decision. The photo showed a wound on the back of the proximal phalanx with oedema and erythema extending to the wrist. The TMAS physician prescribed disinfection, administration of $1 \mathrm{~g}$ of paracetamol every $6 \mathrm{~h}$ and of $1 \mathrm{~g}$ of amoxicillin/clavulanic acid 3 times a day. Given the potential for progression of this presentation, he recommended rerouting the vessel to disembark the patient at the nearest port without helicopter evacuation. The captain refused to reroute his vessel, but the patient was monitored daily by the TMAS physician (monitoring of his temperature and the local appearance). The second photograph, sent $48 \mathrm{~h}$ later, gave an objective view of the clinical improvement under well-managed medical treatment. He disembarked after 4 days and healing was achieved without sequelae (Fig. 5B).

\section{DISCUSSION}

Managing a patient on board a ship has always been the captain's responsibility. The French TMAS provides free, 24-h-a-day service for France for tele-medical consultation and assistance to all sailors or other persons on board any vessel, whether French or foreign. This service must ensure access to care of the best quality possible for all crew members, passengers of the vessel, in collaboration with its different medical, operational, administrative and institutional partners $[1,2]$. In this context, the role of the French TMAS physician is complex. He is a diagnostician 
and a prescriber, accepting full medical responsibility for the decision made; he advises and accompanies the captain. Thus, the on-board care managers and the physicians at the French TMAS practice tele-medicine every day, forming a real couple serving patients on board ships. The French TMAS's activity is constantly on the rise, with 4,928 calls received for 1,814 tele-consultation cases in 2015 .

In order to deal with medical problems, on-board care managers have medical supplies determined according to the kind of navigation practiced; the number and quality of the people present on board and the distance from medical first aid services. This is defined by Division 217 , health and medical provisions [3].

This tele-medicine has evolved and integrated changes proposed on the internet. The transmission of photographs has grown in just a few years [4], with ships being progressively equipped with modern communication resources. This has brought about a revolution in our practices with the presence of photos in one-third of consultation cases.

In all cases, transmissions of photographs were allowed full treatment on board. In first case, despite the severity of the burn no outside intervention, no rerouting of the ship or evacuation of the patient was necessary. In the second case, stitches were applied on board by the captain and in the fourth case, drain of subungual haematoma were applied on board by the captain. In the third case, patient could be treated 4 days before going to consultation. In the latter case, transmitting the photograph made it possible to refine the initial diagnosis, defend the operational decision and monitor the patient who remained on board the vessel.

Easy to do, not very time-consuming, it rounds out the information needed for tele-consultation, makes it possible to monitor care for an injury, to perform reliable dermato- logical examinations, to request the opinion of one of the specialists at Toulouse Hospital, etc. It is done by sending e-mails over the internet with the patient's authorisation without the person's identity appearing in the e-mail, and it is associated with the patient's file in the secured French TMAS software. It has become a vital "tool" for maritime medical tele-consultation. If the captain is "the hands and eyes" of the physician in Toulouse, photographs provide an "eye" on board the ship.

\section{CONCLUSIONS}

The electronic transmission of pictures has already changed our everyday practice in maritime tele-medicine. Current technologies make it possible to develop videoconferencing on board ships, but the technical constraints do not always allow this. Discussions with ship-owners emphasized the heavy financial constraints, but we can hope that videoconferencing capacities will come into general use in the coming years, thus improving our medical practices.

\section{CONFLICT OF INTEREST}

All authors declare that they have no conflicts of interest.

\section{REFERENCES}

1. Interministerial order relative to the operational organization of medical assistance at sea of 29 April 1983. http://www.secourisme. info/pdf/txt595.pdf (last date of access 28 May 2016).

2. Prime Minister's order of 29 August 2011 relative to the organization of medical assistance at sea. http://circulaires.legifrance.gouv.fr/ pdf/2011/11/cir_34077.pdf (last date of access 28 May 2016).

3. French Official Journal of 20 November 1996, Division 217, health and medical provisions. http://www.developpement-durable.gouv. $\mathrm{fr} / \mathrm{IMG} / \mathrm{pdf} / \mathrm{d} 217$ _30-12-15.pdf (last date of access 28 May 2016).

4. Dahl E. Briefing notes on maritime teledermatology. Int Marit Health 2014; 65: 61-64. 